\title{
Acarofauna em cultivo de pinhão-manso e plantas espontâneas associadas
}

\author{
Wilton Pires da Cruz(1), Renato Almeida Sarmento(1), Adenir Vieira Teodoro(2), \\ Eduardo Andrea Lemus Erasmo(1), Marçal Pedro Neto(1), Maíra Ignacio(1) e Diogenis Fontenele Ferreira Junior(1) \\ (1)Universidade Federal do Tocantins, Campus de Gurupi, Programa de Pós-graduação em Produção Vegetal, Caixa Postal 66, \\ CEP 77.402-970 Gurupi, TO.E-mail: wilton@uft.edu.br, rsarmento@uft.edu.br, erasmolemus@uft.edu.br, pedronetom@yahoo.com.br, \\ mairaig@uft.edu.br, diogenis@mail.uft.edu.br (2)Embrapa Tabuleiros Costeiros, Avenida Beira Mar, no 3.250, Jardins, Caixa Postal 44, \\ CEP 49025-040 Aracaju, SE. E-mail: ad.teodoro@cpatc.embrapa.br
}

Resumo - O objetivo deste trabalho foi identificar ácaros na cultura de pinhão-manso e em espécies de plantas espontâneas associadas. Para isso, foram avaliadas a riqueza e a abundância de ácaros em plantas de pinhão-manso e em 14 espécies de plantas espontâneas associadas. As amostragens foram realizadas por meio de coletas mensais de folhas de plantas de pinhão-manso e de plantas espontâneas, nas entrelinhas do cultivo. Foram encontradas quatro espécies de ácaros predadores - Amblyseius tamatavensis, Paraphytoseius multidentatus, Typhlodromalus aripo e Typhlodromalus clavicus -, com potencial para uso no controle biológico de ácaros-praga na cultura do pinhão-manso, e duas importantes espécies de ácaros fitófagos - Brevipalpus phoenicis e Tarsonemus confusus desconhecidas como praga da cultura. Entre as plantas espontâneas avaliadas, quatro espécies - Hyptis suaveolens, Peltaea riedelii, Urochloa mutica e Andropogon gayanus - abrigam grande riqueza e abundância de ácaros predadores, enquanto oito destacaram-se pela diversidade de ácaros fitófagos.

Termos para indexação: Jatropha curcas, controle biológico, fitófagos, plantas invasoras.

\section{Acarofauna in physic nut culture and associated spontaneous weeds}

Abstract-The objective of this work was to identify mites in physic nut culture, and in associated spontaneous weed species. For this, mite richness and abundance on physic nut plants and on 14 species of associated spontaneous weeds were evaluated. Samplings were done with monthy collections of leaves from physic nut plants and from weeds, between planting lines. Four species of predatory mites - Amblyseius tamatavensis, Paraphytoseius multidentatus, Typhlodromalus aripo and Typhlodromalus clavicus -, with potential for biological control of pest mites on physic nut culture, and two species of phytophagous mites - Brevipalpus phoenicis and Tarsonemus confusus -, not yet known as pests of the culture were found. Among the evaluated spontaneous weeds, four species - Hyptis suaveolens, Peltaea riedelii, Urochloa mutica and Andropogon gayanus - harbor great richness and abundance of predatory mites, whereas eight harbored a high diversity of phytophagous mites.

Index terms: Jatropha curcas, biological control, phytophages, invasive plants.

\section{Introdução}

O pinhão-manso (Jatropha curcas L.; Euphorbiaceae) é uma excelente alternativa para a produção de biodiesel entre as espécies potencialmente cultiváveis na região Norte do Brasil (Nóbrega et al., 2011; Sarmento et al., 2011). No entanto, o plantio em larga escala tem gerado grandes problemas, como o ataque de pragas e consequentes prejuízos econômicos. $\mathrm{O}$ ataque de ácaros fitófagos, principalmente das famílias Tetranychidae e Tarsonemidae, constitui o principal problema fitossanitário para o cultivo de pinhão-manso em larga escala (Kavitha et al., 2007; Sarmento et al., 2011). Ácaros predadores são considerados os inimigos naturais mais efetivos no controle biológico de ácaros-praga (Ferla et al., 2007). Entretanto, os ácaros predadores não se alimentam exclusivamente de ácaros fitófagos, pois podem utilizar recursos alternativos, tais como pólen ou néctar de plantas espontâneas (Van Rijn \&Tanigoshi, 1999).

Alguns estudos constataram que a eficiência dos ácaros predadores aumenta na presença de plantas espontâneas, tanto no entorno quanto nas entrelinhas das plantas cultivadas (Bellini et al., 2005). Assim, a maior abundância e riqueza de ácaros predadores, proporcionada pela diversidade de plantas espontâneas, podem favorecer a diminuição de ácaros-praga em cultivos adjacentes (Tsitsilas et al., 2011). Entretanto, as plantas espontâneas também podem abrigar ácaros fitófagos (Duso et al., 2004) que, por sua vez, podem atacar cultivos agrícolas. Estudos sobre a diversidade de 
ácaros predadores e fitófagos, em plantas espontâneas, são necessários para determinar estratégias de controle biológico, assumindo que ambos os grupos podem naturalmente migrar para plantas cultivadas. Trabalhos referentes à identificação de espécies de ácaros predadores e fitófagos, que ocorrem em cultivos de pinhão-manso e em plantas espontâneas associadas, são importantes para o desenvolvimento de estratégias de controle biológico de ácaros-praga na cultura.

O objetivo deste trabalho foi identificar ácaros na cultura de pinhão-manso e em espécies de plantas espontâneas associadas.

\section{Material e Métodos}

O experimento foi conduzido entre fevereiro de 2010 a janeiro de 2011, no Município de Gurupi, TO

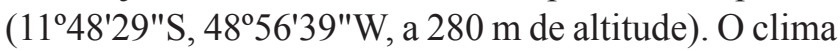
da região é o tropical do tipo Aw segundo Köppen (Brasil, 1992), com duas estações bem definidas no ano: chuvosa, com precipitação pluviométrica de $964,2 \mathrm{~mm}$ e umidade relativa do ar de $80,6 \pm 1,1 \%$, durante os meses de novembro a abril; e seca, com precipitação de $80 \mathrm{~mm}$, e umidade relativa do ar de $59,4 \pm 3,9 \%$, de maio a outubro, durante o período experimental. A temperatura média anual durante os meses de amostragem foi de $26 \pm 0,3^{\circ} \mathrm{C}$. A vegetação nativa da região é de cerrado. As amostragens foram realizadas mensalmente, em uma área de 0,5 ha, cultivada com pinhão-manso, com idade de quatro anos e espaçamento de $3 \times 3 \mathrm{~m}$. Durante o período experimental, as plantas espontâneas foram manejadas somente por meio de roçagem.

A amostragem dos ácaros no pinhão-manso foi realizada em 30 plantas, selecionadas na área de estudo. De cada planta, foram coletadas nove folhas, três em cada estrato da copa (basal, mediano e apical), localizadas da quarta à oitava folha totalmente expandida dos ramos. Ao observar sintomas do ácaro Polyphagotarsonemus latus Banks (1904) (Acari: Tarsonemidae), praga importante do pinhão-manso (Sarmento et al., 2011), em qualquer planta de pinhão-manso da área, também foram feitas coletas entre as três primeiras folhas totalmente expandidas.

As plantas espontâneas foram amostradas com uso da metodologia do quadrado inventário (Braun-Blanquet \& Bolòs, 1979; Erasmo et al., 2004). Foram implantados 15 pontos amostrais de $9 \mathrm{~m}^{2}$ cada um, nas entrelinhas do pinhão-manso. Em cada ponto amostral, foram arremessados dois quadrados de ferro de $0,25 \mathrm{~m}^{2}$ cada um. No interior de cada quadrado foram identificadas as espécies vegetais e contabilizados os indivíduos. Para a identificação, foi utilizada bibliografia especializada e consulta a especialistas. As 14 espécies de plantas espontâneas que apresentaram maior abundância e frequência foram selecionadas para realizar a amostragem de ácaros. As famílias e respectivas espécies selecionadas foram: Família Amaranthaceae - Alternanthera tenella Colla; Fabaceae - Bauhinia angulata Vell., Calopogonium mucunoides Desv., Senna obtusifolia (L.)H.S. Irwin \& Barnaby; Lamiaceae - Hyptis suaveolens (L.) Poit.; Malvaceae - Helicteres guazumifolia Kunth, Peltaea riedelii (Gürke) Standl., Sida cordifolia L., Sida rhombifolia L., Sida urens L., Urena lobata L., Waltheria americana L.; Poaceae - Andropogon gayanus Kunth e Urochloa mutica (Forssk.) T.Q. Nguyen. Para aproximar a área foliar utilizada na amostragem de ácaros, nas diferentes espécies de plantas espontâneas, foram coletadas 10 folhas de cada espécie de dicotiledônea e 20 de cada monocotiledônea, pelo fato de as monocotiledôneas apresentar área foliar menor do que as dicotiledôneas.

Após a coleta de campo, as folhas de pinhão-manso e de plantas espontâneas foram inspecionadas com uso de microscópio estereoscópico (Tecnival SQF-F, Rio Grande do Sul, Brasil) e os ácaros encontrados foram identificados por especialistas da Universidade Federal do Tocantins (UFT) e da University of Amsterdam, Holanda. As lâminas com os espécimes foram depositadas no Laboratório de Entomologia da UFT. A riqueza e a abundância de ácaros foram obtidas com coletas em todas as fases de desenvolvimento, com exceção de ovos, a cada mês, durante o período de coleta.

A riqueza estimada de ácaros, encontrados nas plantas espontâneas e nas de pinhão-manso, foi comparada por meio de curvas de saturação de espécies, pelo estimador Mao Tao, no software Estimates, versão 7.52 (Colwel, 2011). Foram expressos em número de espécies e de indivíduos de ácaros por metro quadrado de área foliar do pinhão-manso ou de plantas espontâneas. Análises de variância para medidas repetidas, excluindo a variância explicada pela sazonalidade, foram realizadas para comparar a abundância de ácaros utilizando o software Statistica 8.0 (StatSoft, 2004). Para haver equivalência entre 
as áreas foliares, foram escolhidos os métodos de estimativa que melhor se ajustariam às características foliares de cada planta estudada. Assim, para obter a área foliar do pinhão-manso, foi utilizado o método de estimativa proposto por Severino et al. (2007). A área foliar das plantas espontâneas foi obtida pelo método de matéria seca e discos foliares, pela fórmula: Área foliar $(\mathrm{AF})=$ (número de discos $\mathrm{x} \mathrm{AD} \times \mathrm{MSF}$ )/MSD, em que, $\mathrm{AD}$, área dos discos; MSF, massa seca da folha e MSD, massa seca dos discos (Lucena et al., 2011), com exceção de $S$. rhombifolia em que foi utilizado o método proposto por Bianco et al. (2008).

\section{Resultados e Discussão}

Nas plantas de pinhão-manso foram encontrados 2.681 ácaros de 28 espécies pertencentes à dez famílias acarinas (Tabela 1). Das famílias de ácaros coletados, quatro continham espécies predadoras (Ascidae, Cunaxidae, Phytoseidae e Iolinidae), três com fitófagos (Tarsonemidae, Tenuipalpidae e Tetranychidae) e três com hábito alimentar indeterminado (Acaridae, Oribatidae e Tydeidae). A família com maior riqueza foi Phytoseiidae, com 16 espécies. As famílias com maior abundância foram Tenuipalpidae, com 1.487 indivíduos, e Phytoseiidae, com 837.

Os predadores corresponderam a $36,5 \%$ do total de ácaros coletados no pinhão-manso. Deste total, 31,2\% pertencia à família Phytoseiidae, que é a família mais importante de ácaros predadores (McMurtry \& Croft, 1997). O ácaro predador Typhlodromalus clavicus Denmark \& Muma (1973), que pode utilizar como fonte de alimento tanto o pólen do pinhão-manso quanto outros ácaros, conforme observado neste trabalho, foi o predador mais abundante encontrado no pinhão-manso, com 17,3\%. Após T. clavicus, os mais abundantes dessa família foram Amblyseius tamatavensis Blommers (1974), Amblyseius sp. e Typhlodromips mangleae DeLeon (1967). Todas as espécies de ácaros fitoseídeos encontrados no pinhão-manso são da subfamília Amblyseinae, confirmando estudos que apontam ser essa a subfamília com maior abundância dentro da família Phytoseiidae (Tixier et al., 2008). O gênero Pronematus, pertencente à família Iolinidae e conhecido como predador (Bellini et al., 2005), correspondeu a $3,7 \%$ dos indivíduos coletados. A família Ascidae apareceu com 1,3\% dos indivíduos coletados, seguida por Cunaxidae, com $0,2 \%$.
Os ácaros fitófagos representaram $59,3 \%$ de todos os ácaros coletados no pinhão-manso. A família Tenuipalpidae apresentou 55,5\% dos espécimes, sendo todos eles Brevipalpus phoenicis (Geijskes, 1939). Esse ácaro é uma importante praga de plantas ornamentais, citrus e café (Feres et al., 2009; Pedro Neto et al., 2010). Porém, não há evidência de danos causados por esse ácaro ao pinhão-manso. Os meses em que ele ocorre coincidem com os meses de maior ocorrência de predadores. Portanto, é possível que essa espécie seja uma importante fonte alimentar para os ácaros predadores. Tarsonemidae foi a segunda família de ácaros fitófagos mais abundante, com 3,5\%. Apesar de estudos anteriores terem encontrado os ácaros-praga Tetranychus bastosi Tuttle, Baker \& Sales (1977) (Acari: Tetranychidae) e P. latus em pinhão-manso (Sarmento et al., 2011), T. bastosi representou apenas $0,4 \%$ do total de indivíduos, e $P$. latus não foi encontrado nesse levantamento.

Foram coletados 9.972 espécimes de 45 espécies de nove famílias acarinas em plantas espontâneas (Tabela 2). Entre as famílias encontradas, quatro são de predadores (Ascidae, Blattisociidae, Phytoseiidae e Stigmaeidae), três de fitófagos (Tetranychidae, Tenuipalpidae e Tarsonemidae) e duas de espécies de hábito alimentar indeterminado (Tydeidae e Acaridae). As famílias de ácaros que apresentaram maior riqueza foram Phytoseiidae e Tetranychidae, com 17 e 10 espécies, respectivamente. As famílias com maior abundância foram Tetranychidae, Tydeidae, Blattisociidae, Tarsonemidae, Tenuipalpidae e Phytoseiidae, em ordem decrescente. Enquanto a família Phytoseiidae é uma importante família de ácaros predadores, a Tetranychidae é uma das mais importantes famílias de ácaros-praga de grande variedade de plantas cultivadas, incluindo o pinhão-manso (Santos et al., 2010; Sarmento et al., 2011).

Entre as 14 espécies de plantas espontâneas estudadas, 13 abrigam ácaros predadores com importância em programas de controle biológico (McMurtry \& Croft, 1997), sendo que, 42,3\% dos ácaros coletados em plantas espontâneas eram predadores. Além disso, 19,2\% desses ácaros pertenciam ao gênero Pronematus da família Iolinidae. Os ácaros predadores Paraphytoseius multidentatus Swirski \& Shechter, 1961 e Typhlodromalus aripo DeLeon (1967) foram os mais abundantes entre as espécies da família Phytoseiidae, com 272 e 
211 indivíduos, respectivamente. Typhlodromalus aripo foi utilizado em programa de controle biológico de Mononychelus tanajoa Bondar (1938) (ácaro-verde-da-mandioca), em vários países da África (Kariuki et al., 2005). Neste estudo esta espécie ocorreu em nove das 14 espécies de plantas estudadas. Typhlodromalus aripo foi a única espécie pertencente à família Phytoseiidae encontrada nas plantas de $U$. lobata e H. suaveolens. Serão necessários experimentos adicionais para avaliar o potencial desse ácaro como agente de controle biológico de ácaros-praga em pinhão-manso.
Os ácaros fitófagos encontrados nas plantas espontâneas somaram $54,9 \%$ do total de ácaros. Tetranychidae foi a família com maior riqueza, com dez espécies. Entre os ácaros-praga dessa família, Mononychellus sp., Mononychellus planki McGregor (1950), Tetranychus spp. e Oligonychus sp. foram os mais abundantes, e compreenderam 1.240, 1.012, 649 e 317 espécimes coletados, respectivamente. Espécies do gênero Tetranychus são pragas de várias culturas, como T. bastosi, que é considerado uma das principais pragas do pinhão-manso (Sarmento et al., 2011). Outras espécies desse gênero também constituem importantes

Tabela 1. Riqueza, abundância (número de indivíduos por $\mathrm{m}^{2}$ de área foliar) e hábito alimentar (P, predador; $\mathrm{F}$, fitófago; I, indeterminado) de ácaros encontrados em plantas de pinhão-manso entre fevereiro de 2010 a janeiro de 2011.

\begin{tabular}{|c|c|c|c|c|c|c|c|c|c|c|c|c|c|c|}
\hline Espécie & Hábito alimentar & Fev. & Mar. & Abr. & Maio & Jun. & Jul. & Ago. & Set. & Out. & Nov. & Dez. & Jan. & Total \\
\hline \multicolumn{15}{|l|}{ Acaridae } \\
\hline Tyrophagus pubescentiae & I & - & - & - & - & - & - & - & - & - & - & - & 27 & 27 \\
\hline Neotropacarus mumai & I & 1 & 26 & 4 & 2 & 2 & - & - & - & - & 14 & 22 & 5 & 76 \\
\hline Acaridae sp. & I & - & - & - & - & - & - & - & - & - & - & 1 & - & 1 \\
\hline \multicolumn{15}{|l|}{ Ascidae } \\
\hline Asca sp. & $\mathrm{P}$ & 1 & 5 & 23 & - & - & - & - & - & - & 5 & 1 & - & 35 \\
\hline \multicolumn{15}{|l|}{ Cunaxidae } \\
\hline Cunaxidae sp. & $\mathrm{P}$ & - & - & - & - & - & - & - & - & - & 2 & 4 & - & 6 \\
\hline \multicolumn{15}{|l|}{ Oribatidae } \\
\hline Oribatidae sp. & I & - & - & - & - & 1 & - & - & - & - & - & 4 & - & 5 \\
\hline \multicolumn{15}{|l|}{ Phytoseiidae } \\
\hline Amblyseius aerialis & $\mathrm{P}$ & - & - & - & - & 13 & - & - & - & - & - & - & - & 13 \\
\hline Amblyseius impressus & $\mathrm{P}$ & - & - & - & - & - & 2 & - & - & - & - & - & - & 2 \\
\hline Amblyseius sp. & $\mathrm{P}$ & - & 19 & - & 26 & 27 & 6 & 4 & - & - & 2 & 7 & 9 & 100 \\
\hline Amblyseius tamatavensis & $\mathrm{P}$ & - & - & 33 & 72 & - & - & - & - & - & - & - & - & 105 \\
\hline Euseius concordis & $\mathrm{P}$ & - & - & - & - & - & - & - & - & - & 9 & - & - & 9 \\
\hline Euseius inouei & $\mathrm{P}$ & - & - & - & - & - & 2 & - & - & - & 2 & - & - & 4 \\
\hline Euseius sp. & $\mathrm{P}$ & - & - & - & - & - & - & - & - & - & 2 & - & - & 2 \\
\hline Iphiseiodes quadripilis & $\mathrm{P}$ & - & - & - & - & 7 & - & - & - & - & - & - & - & 7 \\
\hline Iphiseiodes zuluagai & $\mathrm{P}$ & - & - & - & 12 & - & - & - & - & - & - & - & - & 12 \\
\hline Paraphytoseius multidentatus & $\mathrm{P}$ & 4 & - & - & - & - & - & - & - & - & - & - & - & 4 \\
\hline Proprioseiopsis cannaensis & $\mathrm{P}$ & - & 2 & - & - & - & - & - & - & - & - & - & - & 2 \\
\hline Typhlodromalus aripo & $\mathrm{P}$ & - & 2 & - & 5 & 7 & - & - & - & - & - & - & - & 14 \\
\hline Typhlodromalus clavicus & $\mathrm{P}$ & 65 & 43 & 128 & 69 & 21 & - & - & - & - & 9 & 62 & 67 & 464 \\
\hline Typhlodromips mangleae & $\mathrm{P}$ & - & - & 23 & 26 & 8 & - & - & - & - & - & - & - & 57 \\
\hline Typhlodromatus peregrinus & $\mathrm{P}$ & 4 & 4 & - & - & - & - & - & - & - & - & - & 3 & 11 \\
\hline Typhlodromalus sp. & $\mathrm{P}$ & - & 2 & - & 29 & - & - & - & - & - & - & - & - & 31 \\
\hline \multicolumn{15}{|l|}{ Tarsonemidae } \\
\hline Tarsonemus confusus & $\mathrm{F}$ & - & - & 2 & 7 & - & - & - & - & 11 & 19 & 40 & 4 & 83 \\
\hline Daidalostarsonemus sp. & $\mathrm{F}$ & - & - & - & - & - & - & - & - & - & - & 7 & 4 & 11 \\
\hline \multicolumn{15}{|l|}{ Tenuipalpidae } \\
\hline Brevipalpus phoenicis & $\mathrm{F}$ & 1 & 10 & 252 & 417 & 613 & 190 & - & - & - & - & - & 4 & 1.487 \\
\hline \multicolumn{15}{|l|}{ Tetranychidae } \\
\hline Tetranychus bastosi & $\mathrm{F}$ & - & 2 & 2 & 3 & - & - & - & - & 1 & 2 & - & - & 10 \\
\hline \multicolumn{15}{|l|}{ Tydeidae } \\
\hline Lorryia formosa & I & - & - & - & - & - & 3 & - & - & - & - & - & - & 3 \\
\hline \multicolumn{15}{|l|}{ Iolinidae } \\
\hline Pronematus sp. & $\mathrm{P}$ & - & - & 3 & 2 & - & 7 & - & - & 2 & 68 & 13 & 5 & 100 \\
\hline Total & & 76 & 115 & 470 & 670 & 699 & 210 & 4 & 0 & 14 & 134 & 161 & 128 & 2.681 \\
\hline
\end{tabular}


pragas de diversas culturas, tais como Tetranychus evansi Baker \& Pritchard (1960) e Tetranychus urticae
Koch (1836) (Venzon et al., 2009). Ácaros do gênero Oligonychus também possuem grande importância

Tabela 2. Riqueza e abundância (número de indivíduos por $\mathrm{m}^{2}$ de área foliar) de ácaros encontrados em plantas espontâneas associadas a cultivo de pinhão-manso entre fevereiro de 2010 a janeiro de 2011.

\begin{tabular}{|c|c|c|c|c|c|c|c|c|c|c|c|c|c|c|c|}
\hline Espécie & $\begin{array}{c}A^{(1)} \\
\text { tenella }\end{array}$ & $\begin{array}{l}\text { Bauhinia } \\
\text { angulata }\end{array}$ & $\begin{array}{c}C .^{(2)} \\
\text { nucunoide }\end{array}$ & $\begin{array}{c}\text { Senna } \\
\text { btusifolia }\end{array}$ & $\begin{array}{c}\text { Hyptis } \\
\text { suaveolens }\end{array}$ & $\begin{array}{c}\text { Helicteres } \\
\text { guazumifolia }\end{array}$ & $\begin{array}{l}\text { Peltaea } \\
\text { riedelii }\end{array}$ & $\begin{array}{c}\text { Sida } \\
\text { cordifolia }\end{array}$ & $\begin{array}{c}\text { Sida } \\
\text { a rhombifolia }\end{array}$ & $\begin{array}{c}\text { Sida } \\
\text { urens }\end{array}$ & $\begin{array}{l}\text { Urena } \\
\text { lobata }\end{array}$ & $\begin{array}{l}\text { Waltheria } \\
\text { americana }\end{array}$ & $\begin{array}{c}A^{(3)} \\
\text { gayanus }\end{array}$ & $\begin{array}{c}\text { Urochloa } \\
\text { mutica }\end{array}$ & Total \\
\hline & \multicolumn{15}{|c|}{ Fitófagos } \\
\hline Allonychus sp. & 0 & 0 & 0 & 0 & 0 & 83 & 0 & 0 & 0 & 16 & 0 & 0 & 0 & 0 & 99 \\
\hline Brevipalpus phoenicis & 0 & 6 & 78 & 1 & 0 & 881 & 23 & 0 & 0 & 0 & 34 & 5 & 0 & 5 & 1.033 \\
\hline Daidalotarsonemus sp. & 0 & 0 & 1 & 0 & 0 & 0 & 0 & 0 & 0 & 0 & 0 & 0 & 0 & 0 & 1 \\
\hline Eotetranychus oncora & 0 & 192 & 0 & 0 & 0 & 0 & 0 & 0 & 0 & 0 & 0 & 0 & 0 & 0 & 192 \\
\hline Eotetranychus sp. & 0 & 0 & 0 & 0 & 0 & 0 & 0 & 0 & 0 & 0 & 0 & 74 & 0 & 0 & 74 \\
\hline Fungitarsonemus sp. & 0 & 0 & 0 & 0 & 0 & 0 & 0 & 12 & 0 & 0 & 0 & 0 & 0 & 0 & 12 \\
\hline Mononychellus planki & 0 & 11 & 276 & 0 & 0 & 243 & 5 & 0 & 122 & 0 & 0 & 347 & 8 & 0 & 1.012 \\
\hline Mononychellus sp. & 0 & 0 & 385 & 0 & 0 & 331 & 0 & 20 & 0 & 41 & 7 & 456 & 0 & 0 & 1.240 \\
\hline Oligonychus sp. & 0 & 0 & 0 & 0 & 0 & 0 & 0 & 15 & 0 & 66 & 0 & 0 & 235 & 1 & 317 \\
\hline Panonychus sp. & 0 & 0 & 0 & 0 & 0 & 159 & 0 & 0 & 0 & 0 & 0 & 0 & 0 & 0 & 159 \\
\hline Tarsonemus bilobatus & 0 & 0 & 0 & 0 & 0 & 8 & 0 & 18 & 0 & 0 & 0 & 0 & 0 & 0 & 26 \\
\hline Tarsonemus confusus & 0 & 0 & 15 & 1 & 0 & 54 & 0 & 56 & 16 & 0 & 0 & 18 & 0 & 0 & 160 \\
\hline Tarsonemus sp. & 0 & 1 & 0 & 0 & 2 & 76 & 6 & 0 & 0 & 4 & 140 & 203 & 5 & 19 & 456 \\
\hline Tetranychus bastosi & 0 & 0 & 0 & 0 & 0 & 0 & 0 & 0 & 0 & 10 & 0 & 0 & 0 & 0 & 10 \\
\hline Tetranychus sp. & 1 & 10 & 75 & 2 & 3 & 138 & 17 & 10 & 0 & 50 & 8 & 63 & 252 & 21 & 650 \\
\hline Tetranychus urticae & 0 & 0 & 0 & 0 & 0 & 35 & 0 & 0 & 0 & 0 & 0 & 0 & 0 & 0 & 35 \\
\hline \multirow[t]{2}{*}{ Total } & 1 & 200 & 830 & 4 & 5 & 2.008 & 51 & 131 & 138 & 187 & 189 & 1.166 & 500 & 46 & 5.476 \\
\hline & \multicolumn{15}{|c|}{ Indeterminados } \\
\hline Lorryia formosa & 0 & 11 & 0 & 0 & 0 & 0 & 0 & 0 & 0 & 0 & 0 & 0 & 0 & 0 & 11 \\
\hline Lorryia sp. & 0 & 0 & 0 & 0 & 0 & 0 & 0 & 0 & 0 & 0 & 0 & 32 & 0 & 7 & 39 \\
\hline Neotropacarus mumai & 0 & 17 & 1 & 0 & 1 & 0 & 0 & 30 & 0 & 16 & 3 & 72 & 0 & 3 & 143 \\
\hline Rhizoglyphus sp. & 0 & 0 & 0 & 0 & 0 & 0 & 0 & 0 & 0 & 1 & 0 & 0 & 0 & 0 & 1 \\
\hline Tydeus sp. & 0 & 0 & 0 & 0 & 0 & 0 & 0 & 43 & 0 & 1 & 0 & 0 & 0 & 0 & 44 \\
\hline Tyrophagus putrecentiae & 0 & 2 & 18 & 0 & 0 & 0 & 0 & 0 & 0 & 0 & 0 & 0 & 11 & 0 & 31 \\
\hline Tyrophagus sp. & 0 & 0 & 4 & 0 & 0 & 2 & 0 & 0 & 0 & 0 & 0 & 0 & 0 & 0 & 6 \\
\hline \multirow[t]{2}{*}{ Total } & 0 & 30 & 23 & 0 & 1 & 2 & 0 & 73 & 0 & 18 & 3 & 104 & 11 & 10 & 275 \\
\hline & \multicolumn{15}{|c|}{ Predadores } \\
\hline Aceodromus convolvuli & 0 & 0 & 137 & 0 & 19 & 784 & 8 & 18 & 6 & 48 & 41 & 41 & 23 & 16 & 1.141 \\
\hline Agistemus sp. & 0 & 0 & 0 & 0 & 0 & 0 & 2 & 0 & 0 & 0 & 0 & 0 & 0 & 0 & 2 \\
\hline Amblyseius chiapenis & 0 & 0 & 43 & 0 & 0 & 2 & 11 & 0 & 1 & 22 & 0 & 0 & 0 & 0 & 79 \\
\hline Amblyseius compositus & 0 & 0 & 0 & 0 & 0 & 0 & 0 & 0 & 0 & 0 & 0 & 0 & 5 & 0 & 5 \\
\hline Amblyseius sp. & 0 & 0 & 10 & 0 & 0 & 0 & 3 & 0 & 0 & 6 & 0 & 0 & 10 & 0 & 29 \\
\hline Amblyseius tamatavensis & 0 & 2 & 0 & 0 & 0 & 0 & 0 & 0 & 0 & 0 & 0 & 0 & 0 & 0 & 2 \\
\hline Asca sp. & 0 & 3 & 12 & 0 & 54 & 7 & 34 & 14 & 3 & 15 & 3 & 5 & 0 & 43 & 193 \\
\hline Euseius concordis & 0 & 0 & 0 & 0 & 0 & 2 & 0 & 0 & 0 & 0 & 0 & 0 & 0 & 0 & 2 \\
\hline Neoseiulus affs mumai & 0 & 0 & 0 & 0 & 0 & 0 & 0 & 0 & 0 & 0 & 0 & 0 & 26 & 0 & 26 \\
\hline Neoseiulus bellottii & 0 & 0 & 0 & 0 & 0 & 3 & 0 & 0 & 0 & 0 & 0 & 0 & 0 & 0 & 3 \\
\hline Neoseiulus fallacis & 0 & 0 & 6 & 0 & 0 & 0 & 0 & 0 & 0 & 1 & 0 & 0 & 101 & 0 & 108 \\
\hline Neoseiulus sp. & 0 & 0 & 0 & 0 & 0 & 0 & 7 & 0 & 0 & 0 & 0 & 0 & 0 & 0 & 7 \\
\hline P. multidentatus ${ }^{(4)}$ & 0 & 18 & 0 & 0 & 0 & 57 & 174 & 0 & 0 & 0 & 0 & 23 & 0 & 0 & 272 \\
\hline Paraphytoseius sp. & 0 & 0 & 0 & 0 & 0 & 0 & 13 & 0 & 0 & 0 & 0 & 9 & 0 & 0 & 22 \\
\hline Phytoseiulus sp. & 0 & 2 & 0 & 0 & 0 & 141 & 0 & 1 & 0 & 0 & 0 & 4 & 0 & 0 & 148 \\
\hline Pronematus sp. & 0 & 0 & 12 & 0 & 3 & 45 & 4 & 68 & 0 & 27 & 7 & 305 & 1.335 & 113 & 1.919 \\
\hline P. cannaensis $^{\left({ }^{(5)}\right.}$ & 0 & 0 & 0 & 0 & 0 & 0 & 0 & 0 & 0 & 2 & 0 & 0 & 0 & 0 & 2 \\
\hline Typhlodromalus aripo & 0 & 4 & 38 & 0 & 74 & 0 & 21 & 0 & 7 & 0 & 14 & 19 & 28 & 6 & 211 \\
\hline Typhlodromalus clavicus & 0 & 18 & 0 & 0 & 0 & 0 & 3 & 0 & 0 & 0 & 0 & 0 & 0 & 0 & 21 \\
\hline Typhlodromips mangleae & 0 & 0 & 16 & 0 & 0 & 0 & 0 & 0 & 0 & 0 & 0 & 0 & 0 & 10 & 26 \\
\hline Typhlodromalus sp. & 1 & 0 & 0 & 0 & 0 & 0 & 0 & 0 & 0 & 0 & 0 & 0 & 0 & 0 & 1 \\
\hline Zetzellia sp. & 0 & 0 & 0 & 0 & 0 & 0 & 2 & 0 & 0 & 0 & 0 & 0 & 0 & 0 & 2 \\
\hline Total & 1 & 47 & 274 & 0 & 150 & 1.041 & 282 & 101 & 17 & 121 & 65 & 406 & 1.528 & 188 & 4.221 \\
\hline Total geral & 2 & 297 & 1.127 & 4 & 156 & 3.051 & 333 & 305 & 155 & 326 & 257 & 1.676 & 2.039 & 244 & 9.972 \\
\hline
\end{tabular}

${ }^{(1)}$ Alternanthera. ${ }^{(2)}$ Calopogonium. ${ }^{(3)}$ Andropogon. ${ }^{(4)}$ Paraphytoseius. ${ }^{(5)}$ Proprioseiopsis. 
agrícola, como Oligonychus ilicis McGregor (1917), considerada uma das principais pragas do cafeeiro e $O$. yothersi que é encontrado em cultivos de erva-mate (Alves et al., 2004; Teodoro et al., 2008; Pedro Neto et al., 2010). A família Tarsonemidae apresentou a segunda maior riqueza, com cinco espécies encontradas nas plantas espontâneas, e o gênero Tarsonemus apresentou 456 indivíduos.

As espécies espontâneas $H$. guazumifolia, C. mucunoides, $W$. americana, $P$. riedelii e $S$. urens hospedaram maior riqueza e abundância de ácaros com 19 espécies e 3.051 indivíduos, 17 e 1.127, 16 e 1.676, 16 e 333, 16 e 326, respectivamente. Andropogon gayanus destacou-se, principalmente, devido à abundância, com 2.039 indivíduos e 12 espécies de ácaros. Bauhinia angulata, S. cordifolia, U. mutica, $U$. lobata, H. suaveolens e $S$. rhombifolia apresentaram, respectivamente, 14 e 297, 12 e 305, 11 e 244, 9 e 257, 7 e 156, 6 e 155 espécies e indivíduos de ácaros. Em S. obtusifolia, foram encontradas duas espécies e um gênero, no total de quatro ácaros, e em $A$. tenella, dois indivíduos pertencentes a gêneros e famílias diferentes.

As espécies de plantas espontâneas, que abrigaram maior abundância de ácaros predadores com relação aos ácaros fitófagos, foram $B$. suaveolens (96,2\%), $P$. riedelii $(84,7 \%), \quad U$. mutica $(76,9 \%)$ e A. gayanus (74,9\%). Em $H$. suaveolens, o predador T. aripo destaca-se pela grande abundância em relação aos outros ácaros. A riqueza de ácaros encontrados nessa espécie de planta não foi expressiva, sendo quatro predadores e dois fitófagos. A planta P. riedelii, por outro lado, teve destaque tanto com relação ao número de indivíduos de ácaros predadores encontrados, quanto à riqueza, com 12 predadores e quatro fitófagos. A família Stigmaeidae, representada pelos gêneros Agistemus e Zetzellia, ocorreu somente nessa espécie de planta. De acordo com observação de campo, $P$. riedelii produziu grande quantidade de pólen durante a floração, sendo esse pólen utilizado como alimento alternativo para ácaros predadores (Van Rijn \& Tanigoshi, 1999). O número de indivíduos de ácaros predadores pertencentes ao gênero Pronematus, encontrados nas espécies $U$. mutica $(45,9 \%)$ e A. gayanus (65,5\%), foi expressivo. Quanto à riqueza de ácaros, cinco predadores e quatro fitófagos ocorreram em $U$. mutica e sete predadores e quatro fitófagos em A. gayanus.

As plantas espontâneas que abrigaram maior abundância de ácaros fitófagos, quando comparadas ao número de ácaros predadores, foram $S$. rhombifolia $(89,0 \%)$, B. angulata $(74,2 \%)$, C. mucunoides $(73,6 \%), U$. lobata (73,5\%), W. americana $(69,6 \%), H$. guazumifolia (65,8\%), S. cordifolia $(65,3 \%)$ e $S$. urens $(57,2 \%)$. O ácaro M. planki ocorreu em $78,7 \%$ das coletas realizadas em S. rhombifolia. Quatro espécies de predadores e duas de fitófagos foram encontradas nessa planta. Em B. angulata, $65,1 \%$ dos ácaros eram de Eotetranychus ancora Baker \& Pritchard (1960), apesar da riqueza de seis predadores e cinco fitófagos. A riqueza de ácaros predadores encontrados em $C$. mucunoides foi alta, com oito espécies e seis de fitófagos. Entretanto, Tetranychidae foi a família com maior número de ácaros, com destaque para M. planki. Dos ácaros encontrados em $U$. lobata, $54,5 \%$ pertenciam ao gênero Tarsonemus, sendo encontradas, pelo menos, outras três espécies fitófagas e quatro predadoras. Entre os ácaros encontrados em $W$. americana, $56,1 \%$ pertenciam à família Tetranychidae, sendo M. planki a de maior ocorrência. Sete espécies de ácaros predadores e sete de fitófagos foram encontradas nessa planta. Em H. guazumifolia, foram encontrados dez fitófagos e oito predadores, sendo o fitófago $B$. phoenicis o de maior número de indivíduos $(28,9 \%)$. Em $S$. cordifolia ocorreram sete espécies de ácaros fitófagos e três de predadores, dos quais 22,3\% pertenciam a Pronematus sp. e $18,4 \%$ a Tarsonemus confusus Ewing (1939) (Acari: Tarsonemidae). Seis espécies de fitófagos e sete de predadores ocorreram em $S$. urens. Desses indivíduos, $51,1 \%$ eram da família Tetranychidae.

A riqueza de ácaros predadores em pinhão-manso foi maior em relação aos ácaros fitófagos (Figuras 1 e 2). Os indivíduos das famílias Cunaxidae e Oribatidae foram encontrados somente em plantas de pinhão-manso. A riqueza de ácaros predadores também foi maior em comparação à riqueza de fitófagos em plantas espontâneas (Figura 1). O número total de ácaros encontrados nas plantas espontâneas foi maior do que o total de ácaros encontrados na cultura do pinhão-manso (Figura 2).

No pinhão-manso, a abundância de ácaros $(22,2 \pm 1,3)$ foi maior do que em plantas espontâneas $(14,1 \pm 1,9)$ $(\mathrm{F} 1,42=12,257 ; \mathrm{P}=0,001 ; \mathrm{n}=42)$. A existência de rica acarofauna, tanto no pinhão-manso quanto nas plantas espontâneas associadas, pode favorecer ácaros predadores, que podem contribuir para a redução de ácaros-praga. A riqueza e abundância de predadores 


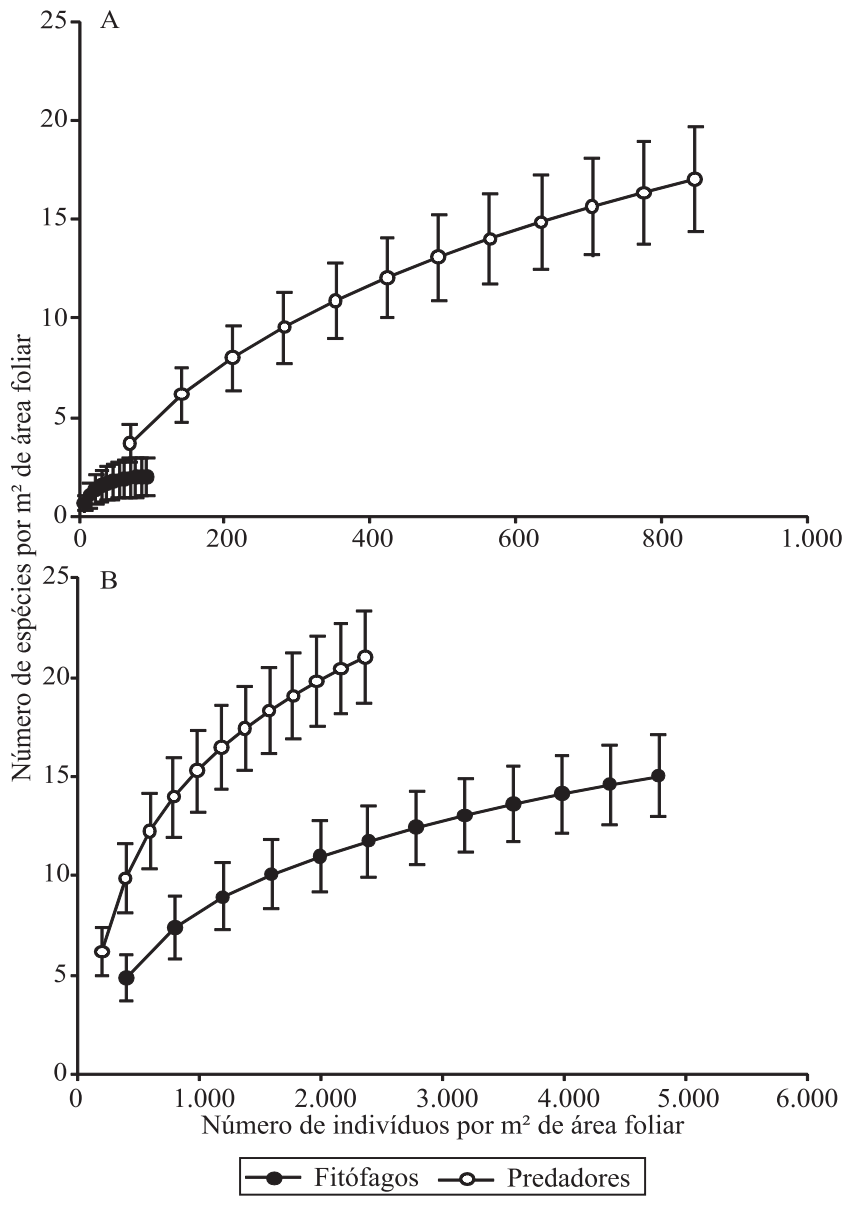

Figura 1. Curvas de saturação de espécies de ácaros predadores e fitófagos encontrados em A, plantas de pinhão-manso; e B, plantas espontâneas associadas, geradas pelo estimador Mao Tao. Barras representam erro-padrão.

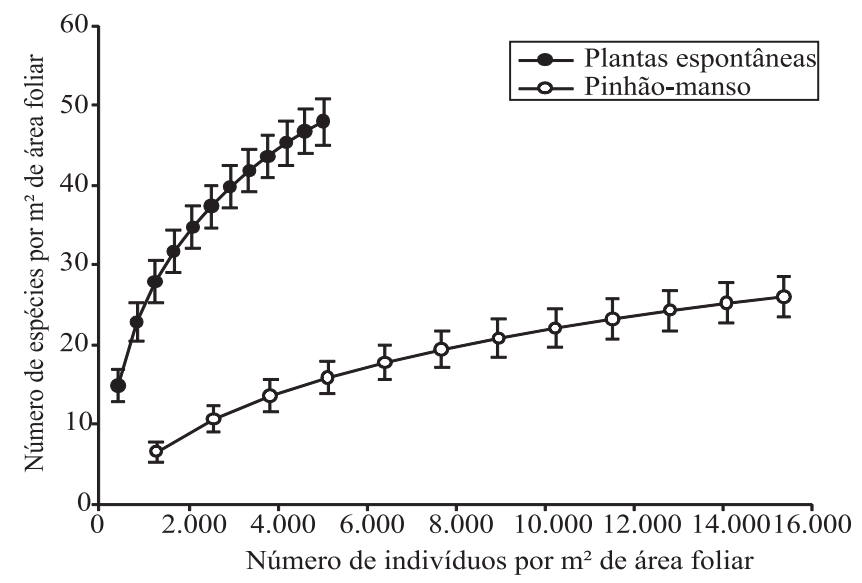

Figura 2. Curvas de saturação de espécies padronizadas pelos números de espécies de ácaros encontrados em plantas de pinhão-manso e em plantas espontâneas associadas a uma área de cultivo de pinhão-manso geradas pelo estimador Mao Tao. As barras representam erro-padrão. podem ter contribuído para a baixa população de T. bastosi. Vários estudos em plantas apontam que ácaros predadores generalistas, com destaque para a família Phytoseiidae, são mais abundantes do que ácaros predadores específicos (Ferla et al., 2007; Bellini et al., 2008; Sudo et al., 2010). Os ácaros predadores generalistas têm a vantagem competitiva de utilizar uma infinidade de alimentos, tais como, fungos, pólen, nectar e presas, que podem ser tanto ácaros quanto insetos (McMurtry \& Croft, 1997). Portanto, parte dos recursos alimentares desses ácaros tornam-se disponíveis por meio das plantas espontâneas (Isaacs et al., 2009), que faz com que os predadores permaneçam no local quando há escassez de alimento fornecido pela própria cultura ou pelos ácaros-praga que atacam a cultura (Oliveira et al., 2007; Fiedler et al., 2008; Tsitsilas et al., 2011).

\section{Conclusões}

1. Os ácaros predadores Amblyseius tamatavensis, Paraphytoseius multidentatus, Typhlodromalus aripo, Typhlodromalus clavicus, Amblyseius sp., e Pronematus sp. são potenciais inimigos naturais de ácaros-praga em pinhão-manso.

2. Os ácaros fitófagos Brevipalpus phoenicis e Tarsonemus confusus são potenciais ácaros-praga do pinhão-manso.

3. As plantas espontâneas Hyptis suaveolens, Peltaea riedelii, Urochloa mutica e Andropogon gayanus apresentam potencial para manutenção de ácaros predadores na cultura de pinhão-manso.

4. As plantas espontâneas, Sida rhombifolia, Bauhinia angulata, Calopogonium mucunoides, Urena lobata, Waltheria americana, Helicteres guazumifolia, Sida cordifolia e Sida urens, são hospedeiras de ácaros fitófagos, quando associadas a cultivos de pinhão-manso.

\section{Agradecimentos}

Ao Conselho Nacional de Desenvolvimento Científico e Tecnológico, pelo apoio financeiro; à Coordenação de Aperfeiçoamento de Pessoal de Nível Superior, pelo apoio financeiro e concessão de bolsas; ao Dr. Farid Faraji da University of Amsterdam, Holanda, pela identificação dos ácaros. 


\section{Referências}

ALVES, L.F.A.; SPONGOSKI, S.; VIEIRA, F.N. da S.; MORAES, G.J. de. Biologia e danos de Oligonychus yothersi (McGregor) (Acari: Tetranychidae) em Ilex paraguariensis. Arquivos do Instituto Biológico, v.71, p.211-214, 2004.

BELLINI, M.R.; FERES, R.J.F.; BUOSI, R. Ácaros (Acari) de seringueira (Hevea brasiliensis Muell. Arg., Euphorbiaceae) e de euforbiáceas espontâneas no interior dos cultivos. Neotropical Entomology, v.37, p.463-471, 2008.

BELLINI, M.R.; MORAES, G.J. de; FERES, R.J.F. Plantas de ocorrência espontânea como substratos alternativos para fitoseídeos (Acari, Phytoseiidae) em cultivos de seringueira Hevea brasiliensis Muell. Arg. (Euphorbiaceae). Revista Brasileira de Zoologia, v.22, p.35-42, 2005.

BIANCO, S.; CARVALHO, L.B.; BIANCO, M.S. Estimativa da área foliar de Sida cordifolia e Sida rhombifolia usando dimensões lineares do limbo foliar. Planta Daninha, v.26, p.807-813, 2008.

BRASIL. Ministério da Agricultura e Reforma Agrária. Departamento Nacional de Meteorologia. Normais climatológicas (1961-1990). Brasília: MAPA, 1992. 84p.

BRAUN-BLANQUET, J.; BOLÒS, O. de. Fitosociología: bases para el estudio de las comunidades vegetales. Madrid: H. Blume, 1979. 820p.

COLWEL, R.K. End-user agreement for Estimates. Version 7.52. Storrs: University of Connecticut, 2011.

DUSO, C.; MALAGNINI, V.; PAGANELLI, A.; ALDEGHERI, L.; BOTTINI, M.; OTTO, S. Pollen availability and abundance of predatory phytoseiid mites on natural and secondary hedgerows. BioControl, v.49, p.397-415, 2004.

ERASMO, E.A.L.; PINHEIRO, L.L.A.; COSTA, N.V. Levantamento fitossociológico das comunidades de plantas infestantes e áreas de produção de arroz irrigado cultivado sob diferentes sistemas de manejo. Planta Daninha, v.22, p.195-201, 2004.

FERES, R.J.F.; VIEIRA, M.R.; DAUD, R.D.; PEREIRA JÚNIOR, E.G.; OLIVEIRA, G.F.; DOURADO, C.L. Ácaros (Arachnida, Acari) de plantas ornamentais na região noroeste do estado de São Paulo, Brasil: inventário e descrição dos sintomas causados pelos fitófagos. Revista Brasileira de Entomologia, v.53, p.466-474, 2009.

FERLA, N.J.; MARCHETTI, M.M.; GONÇALVES, D. Ácaros predadores (Acari) associados à cultura do morango (Fragaria sp., Rosaceae) e plantas próximas no Estado do Rio Grande do Sul. Biota Neotropical, v.7, p.1-8, 2007.

FIEDLER, A.K.; LANDIS, D.A.; WRATTEN, S.D. Maximizing ecosystem services from conservation biological control: the role of habitat management. Biological Control, v.45, p.254-271, 2008.

ISAACS, R.; TUELL, J.; FIEDLER, A.; GARDINER, M.; LANDIS, D.A. Maximizing arthropod-mediated ecosystem services in agricultural landscapes: the role of native plants. Frontiers in Ecology and the Environment, v.7, p.196-203, 2009.

KARIUKI, C.W.; HANNA, R.; TOKO, M. The impact of a predatory mite, Typhlodromalus aripo De Leon (Acari: Phytoseiidae) on cassava green mite population and yield of cassava in the field. African Crop Science Conference Proceedings, v.7, p.1401-1405, 2005.

KAVITHA, J.; RAMARAJU, K.; BASKARAN, V.; PRETHEEP, K.P. Bioecology and management of spider mites and broad mites occurring on Jatropha curcas L. in Tamil Nadu, India. Systematic and Applied Acarology, v.12, p.109-115, 2007.

LUCENA, R.R.M. de; BATISTA, T.M. de V.; DOMBROSKI, J.L.D.; LOPES, W. de A.R.; RODRIGUES, G.S. de O. Medição de área foliar de aceroleira. Revista Caatinga, v.24, p.40-45, 2011.

MCMURTRY, J.A.; CROFT, B.A. Life-styles of phytoseiid mites and their role in biological control. Annual Review of Entomology, v.42, p.291-321, 1997.

NÓBREGA, J.A. da; AZEVEDO, C.A.V. de; DANTAS NETO, J.; NASCIMENTO, J.J.V.R. do; GOUVEIA NETO, G. da C. Efeito de tipos de adubação e lâminas de água salina em folhas de pinhão-manso em condiçoes de campo. Revista Brasileira de Agricultura Irrigada, v.5, p.63-67, 2011.

OLIVEIRA, H.; DUARTE, V.; REZENDE, D.; FADINI, M.A.M.; PALLINI, A. Períodos de ausência de presas e estabilidade do controle biológico do ácaro-rajado. Pesquisa Agropecuária Brasileira, v.42, p.1207-1209, 2007.

PEDRO NETO, M.; REIS, P.R.; ZACARIAS, M.S.; SILVA, R.A. Influência do regime pluviométrico na distribuição de ácaros em cafeeiros conduzidos em sistemas orgânico e convencional. Coffee Science, v.5, p.67-74, 2010.

SANTOS, H.O. dos; SILVA-MANN, R.; BOARI, A. de J. Tetranychus bastosi Tuttle, Baker \& Sales (Prostigmata: Tetranychidae) mites on Jatropha curcas (Linaeus) in Sergipe State, Brazil. Comunicata Scientiae, v.1, p.153-155, 2010.

SARMENTO, R.A.; RODRIGUES, D.M.; FARAJI, F.; ERASMO, E.A.; LEMOS, F.; TEODORO, A.V.; KIKUCHI, W.T.; SANTOS, G.R. dos; PALLINI, A. Suitability of the predatory mites Iphiseiodes zuluagai and Euseius concordis in controlling Polyphagotarsonemus latus and Tetranychus bastosi on Jatropha curcas plants in Brazil. Experimental and Applied Acarology, v.53, p.203-214, 2011.

SEVERINO, L.S.; VALE, L.S.; BELTRÃO, N.E.M. A simple method for measurement of Jatropha curcas leaf area. Revista Brasileira de Oleaginosas e Fibrosas, v.11, p.9-14, 2007.

STATSOFT. Statistica for Windows: software system for data-analyses. Version 8.0. Tulsa: StatSoft, 2004.

SUDO, M.; NISHIDA, S.; ITIOKA, T. Seasonal fluctuations in foliar mite populations on Viburnum erosum Thunb. var. punctatum Franch. et Sav. (Adoxaceae) and sympatric shrubs in temperate secondary forests in western Japan. Applied Entomology and Zoology, v.45, p.405-415, 2010.

TEODORO,A.; KLEIN,A.-M.; TSCHARNTKE, T. Environmentally mediated coffee pest densities in relation to agroforestry management, using hierarchical partitioning analyses. Agriculture, Ecosystems and Environment, v.125, p.120-126, 2008.

TIXIER, M.-S.; KREITER, S.; MORAES, G.J. de. Biogeographic distribution of the Phytoseiidae (Acari: Mesostigmata). Biological Journal of the Linnean Society, v.93, p.845-856, 2008. 
TSITSILAS, A.; HOFFMANN, A.A.; WEEKS, A.R.; UMINA, P.A. Impact of groundcover manipulations within windbreaks on mite pests and their natural enemies. Australian Journal of Entomology, v.50, p.37-47, 2011.

VAN RIJN, P.C.J.; TANIGOSHI, L.K. Pollen as food for the predatory mites Iphiseius degenerans and Neoseiulus cucumeris
(Acari: Phytoseiidae): dietary range and life history. Experimental and Applied Acarology, v.23, p.785-802, 1999.

VENZON, M.; LEMOS, F.; SARMENTO, R.A.; ROSADO, M.C.; PALLINI, A. Predação por coccinelídeos e crisopídeo influenciada pela teia de Tetranychus evansi. Pesquisa Agropecuária Brasileira, v.44, p.1086-1091, 2009.

Recebido em 22 de novembro de 2011 e aprovado em 24 de fevereiro de 2012 